\title{
DIE LEER VAN CALVYN OOR DIE SEKERHEID VAN DIE GELOOF
}

\author{
Prof. P. J. Coetzee
}

Die Reformasie van die sestiende eeu het ten diepste 'n religieuse oorsprong gehad. Dit is uit die diepgevoelde behoefte aan sekerheid van die heil gebore. Baie duidelik spreek dit in die Belydenisskrifte wat die gees van die Hervorming adem. Vergelyk bv. antwoorde 1, 21, 26, 28, 32, 39, 44, 52, 54 en so meer van die Heidelbergse Kategismus. Daar word dan veral ook gevra na hierdie sekerheid vir die persoonlike lewe. S. van der Linde' se aanvoeling is dat die Reformasie se kosbaarste bydrae die feit is dat die geloof "herontdek" is en dat die stryd vir die waarheid van God met die slagspreuk gevoer is: Sola fide!

Nou is dit veelseggend - aldus Van der Linde - dat Calvyn, wanneer hy oor die geloof handel, begin met juis aan die sekerheid van die geloof aandag te gee. L. Berkhof wys ook daarop dat Calvyn die sekerheid van die geloof as 'n kosbare pêrel op die voorgrond gestel het. ${ }^{2}$ Niemand het hom meer spesifiek rekenskap gegee van wat hierdie sekerheid behels as Calvyn nie. Dit het sy hart met blye hoop vervul. ${ }^{3}$ Volgens Calvyn is die geloof certa, firma, plena et fixa certitudo. Dit is meer certitudo as apprehensio, dit is cordis fiducia et securitas4. Die Gees van God beseël die ware geloof in ons harte.

Ons benader Calvyn se siening van die sekerheid van die geloof onder drie gesigspunte:

A. Die noodsaaklikheid van die sekerheid van die geloof.

B. Die grond van hierdie sekerheid en

C. Die vreugde wat die sekerheid bied.

A. Die noodsaaklikheid van die Sekerheid van die geloof

Calvyn lê sterk nadruk daarop dat die geloof sekerheid inhou en vereis (indikatief en imperatief). ,'n Volle en bepaalde sekerheid". ${ }^{5}$ Hy neem dus radikaal standpunt in teen die Roomse leer waarvolgens daar nie sprake van heilsekerheid kan wees nie. Die Roomse Kerk erken nie dat die sekerheid van die geloof ook insluit die volstrekte versekerheid van die eie saligheid (certitudo salutis) nieb. Hulle handhaaf dat die volkome versekerheid van ewige heil slegs die deel van enkele gelowiges, veral martelare, word wat dit aan 'n bykomstige besondere openbaring te danke het. Die geloof is blote verstandelike toestemming, sonder die element van persoonlike sekerheid. Dit vloei dus nie voort uit de aard van geloof nie. H. Bavinck wys daarop dat daar in die Roomse stelsel vir hierdie sekerheid geen plek is nie, omdat dit alleen bestaanbaar is by die belydenis van God se verkiesende liefde. Rome skram ook daarvan weg omdat dit die sg. „leke" van die kerk en die priester onafhanklik sou maak?. Die Roomse teoloë erken egter die certitudo fidei ten opsigte van die 
objektiewe waarhede van die openbaring. Augustinus stel dit so in sy Confessiones ${ }^{8}$ : „Facilius dubitarem vivere me, quam non esse veritatem, quae per ea, quae facta sunt, intellecta conspicitur." Albertus Magnus maak onderskeid tussen geloof in die filosofie en in die teologie. By die filosofie is geloof niks anders as credulitas en geen weg tot kennis nie; maar ,in theologicis fides lumen est, certissimam faciens adhaesionem et assensum... et ideo est via et medium ad scientiam veritatis divinorum." Die gewone gelowiges (leke) het ten aansien van hulle saligheid volgens Rome slegs 'n certitudo moralis, conjecturalis, maar geen certitudo fidei nie.

Anders as Rome is Calvyn se uitgangspunt dat die sekerheid van die geloof noodsaaklik is. Hy distansieer hom van die Roomse leer van die „coniectura moralis" wat impliseer dat 'n mens lewenslank moet bly twyfel en in onsekerheid verkeer, veral in die lig van die steeds in onsekerheid hangende vraag of jy sal volhard. Calvyn noem hierdie leer duiwels en goddeloos'. Hy het nie vrede met die leer van die (fides implicita,) die ingewikkelde geloof, by Rome nie. Dit is 'n geloof waarvan ons die inhoud nie hoef te ken nie maar ons neem dit aan omdat die kerk dit met sy gesag dek. Reeds in die begin van sy Institusie stel Calvyn hom teenoor hierdie Roomse leer van die „,ingewikkelde geloof" (fides implicita). Hy bestempel hierdie sogenaamde geloof as ' $n$ baie growwe onwetenheid. Hy beskou dit as ' $n$ uitvinding van die Skolastieke. Calvyn sê die geloof is nie in onwetenheid geleë nie, maar in kennis. Die taak om te ondersoek en te leer ken mag ons nie aan die kerk oorlaat nie ${ }^{10}$. Rome het dit verskriklik ingewikkeld gemaak. Daar is natuurlik sake wat wel ingewikkeld is, maar dit hou verband met dinge wat nog, terwyl ons sien deur 'n spieël in 'n raaisel, opgeklaar moet word". Veel is vir ons nog verborge en ons is deur vele newels van dwalinge omring sodat ons nie alles verstaan nie. Calvyn wys dan op die dissipels, voordat hulle die volle opheldering ontvang het, en op die vroue in die geskiedenis van die opstanding van Christus. Die geloof is altyd nog met ongeloof vermeng ${ }^{12}$.

In sy beklemtoning van die noodsaaklikheid van die sekerheid van die geloof wys Calvyn die Roomse onderskeiding tussen ,gevormde" en "ongevormde" geloof uitdruklik af ${ }^{13}$. Hy doen dit, terwyl hy dit as 'n dwase onderskeiding bestempel, en hulle gevoelens as 'n "ongerymde versinsel" op grond daarvan dat die begin van te glo reeds die versoening in Christus inhou waardeur die mens tot God kan nader. Daarom kan dit nooit 'n verstandelike toestemming sonder meer wees nie. Hierdie instemming is volgens Calvyn meer ' $n$ saak van die hart as van die verstand alleen. Dit behels meer die gesindheid (assensio cordis magis quam cerebri, et affectus magis quam intelligentiae). Die geloof met sy onmisbare inherente sekerheid gaan by Calvyn gepaard met ' $n$ lewendige gevoel, meestal af te grens teenoor die verstand en die naturae sensus. Daarom, sê Calvyn, word dit gehoorsaamheid van die geloof genoem. Hy verwys dan na Rom. 1.5 en Joh. 3.33. 


\section{B. Die grond van die sekerheid van die geloof}

Tereg bely Calvyn dat die sekerheid van die geloof in die openbaring van God in Christus gefundeer is. In die Ou Testament vind die betrekking van God se volk tot Jahwe, die God van die verbond, sy diepste vertolking in die woord ,geloof". Die Hebreeuse woord daarvoor is afgelei van ' $n$ stam wat vastheid, betroubaarheid beteken. Nou verwant daarmee is die bekende woord ,amen" wat die Heidelbergse Kategismus weergee met: Dit sal waar en seker wees. Jy ag 'n persoon betroubaar, waaragtig, en handel daarna. God word as betroubaar erken, vir Hom sê ons amen, met al die konsekwensies daaraan verbonde. Die betrekking waarin God Self Hom tot sy volk in bevele of genadebetoon stel, word geken en erken, om ten volle daaruit te lewe (Gen. 15.6). Die geloof omspan en stempel die hele bestaan. Dit rus in die betrekking waarin God Hom tot sy verbondsvolk gestel het. Dit sien dus op God se genadige verkiesing, sy guns en goedertierenheid. Om te glo is om daarop amen te sê, om dit ten volle te erken, jou ganse lewe daardeur te laat beheers, daaruit moed en vertroue te put selfs in die mees kritieke omstandighede $\mathrm{e}^{14}$.

In die Nuwe Testament beteken om te glo om die verkondigde Woord te aanvaar, om daaruit te lewe, om daarop te vertrou en jou lewe daarvolgens in te rig. Ons geloof rus op Christus wat in die Evangelie tot ons kom. En dit is die Heilige Gees wat vir ons die vertroue wekkende karakter van God se beloftes wat in Christus ja en amen is, ontsluit. Die geloof staan teenoor besorgheid (Matth. 6.31; $8.26 ; 10.31$ ), vrees (Mark. 4.40; 5.36), twyfel (Matth. 14.31; 21.21; Rom. 4.20; Jak. 1.6). Dit is onbeperkte vertroue (Matth. 17.20),

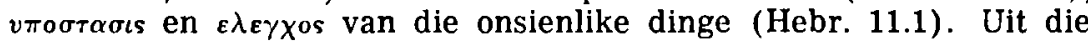
versekerdheid van die geloof jubel die vromes van die Ou en Nuwe Verbond (Gen. 49.18; Ps. 16.8-10; 23.4-6; 31.2; 56.5, 10; 57,3 e.v.; Rom. $4.18,21 ; 8.38)$. Na sy aard en wese sluit die geloof die sekerheid in. Hierdie sekerheid wat betrekking het sowel op die objektiewe genade van God in Christus as op die subjektiewe gemeenskap wat die gelowige daarmee besit, kom nie van buite af die geloof toe nie, maar lê van die begin af in beginsel daarin opgesluit. Dit word nie verkry deur op onsself, maar deur van onsself af op Christus te sien. Dit het sy grondslag en vastigheid in die beloftes van God en nie in die wisselende bevindinge of die onvolkome goeie werke nie ${ }^{15}$. Die geloof maak die onsienlike dinge van die heil so seker vir ons, ja veel sekerder as eie insig of ' $n$ wetenskaplike bewys dit ooit kan doen.

Daarom is daar in die Heilige Skrif spake van $\pi \alpha \rho \rho \eta \sigma \iota \alpha$ (Hebr. 4.16), $\pi \varepsilon \pi \circ \iota \theta \eta \sigma \iota s$ (Efes. 3.12) $\pi \lambda \eta \rho \circ \phi o \rho \iota \alpha$ (Heb. 6.11, 12; 10.22) van die geloof. Aan die geloof word $\theta \alpha \rho \sigma o s$ (Matth. 9.2), $\kappa \alpha v \chi \pi \sigma \iota s$ (Rom. 5.2), $\chi^{\alpha \rho} \iota s$ (1 Petr. 1.8) ens. toegeskrywe ${ }^{16}$. Sekerheid word deur die hele Skrif as 'n kenmerk van die geloof wat 'n gawe van God is (Efes. 2.8 , voorgehou. Dit hou selfs in die grootste beproewing die gelowige staande as siende die onsienlike (Joh. 19.25; Ps. 23.32; 51; Rom. 4.20, 21; 5.1; 8.38; Hebr. 11). Niks is so kosbaar as die geloof

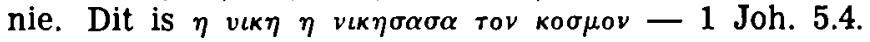


Ons bely dat die geloof wat alleen ons Christus en al sy weldade deelagtig maak, van die Heilige Gees kom (Heid. Kategismus, Sond. 25). Daarom kan Calvyn verklaar dat die geloof 'n inherente sekerheid het. Die Heilige Gees wat dit verseël, mak dit vas' ${ }^{17}$. Die Heilige Gees het by die lewende geloof wat nie kan sterwe nie, 'n vaste woonplek. Hy lê daarin onoorwinlike $\mathrm{krag}^{18}$. Die geloof is 'n seldsame, besondere gawe van die Heilige Gees (,fides singulare Dei donum ... electionis fructus"). Hy ontleen sy sekerheid nie aan iets van of in die mens nie, maar aan die Heilige Gees. Hier is sprake van die ware geloof, in onderskeiding van alle valse munt wat hulle as eg aansien. Die waaragtige geloof tot saligheid is 'n vrug van die wedergeboorte wat geheel-en-al die werk van die Heilige Gees is (Joh. 3). Dit het nie, soos die tydgeloof, sy setel net in die gemoedsaandoeninge, die gevoel, nie, terwyl die hart intussen hard en onvernuut bly (Luk. 8.13) ${ }^{19}$. Die Heilige Gees het alles te maak met die sekerheid van die geloof (vgl. Sond. 1, Heid. Kateg., Sond. 7, Sond. 20; Efes. 1.13, 14). D e Heilige Gees alleen laat die Woord van God in ons hart ingang vind en gee die sekerheid riat wat God ons in sy Woord belowe, ons deel is. Hy laat hierdie sekerheid ook toeneem ${ }^{20}$.

D'e Skolastieke beskuldig Calvyn dat hy ydel roem in die Heilige Gees. Calvyn sê hulle bewys daardeur dat hulle van die geloof heeltemal niks begryp het nie. Hoe sou hulle ook waar die „certamina conscientiae" vir hulle so vreemd gebly het.

Juis aan d'e Heilige Gees en sy verligting en verseëling is dit te danke dat die geloof 'n onoorwinlike sekerheid ken: „illa inexpugnabilis securitas". Daar is vir God geen groter lof en eer as wanneer sy Woord so ' $n$ vaste geloof vind nie. Sonder hierdie roem bestaan die Christendom nie.

\section{Cognitio}

Calvyn noem die geloof ' $n$ vaste en sekere kennis ${ }^{21}$. Dit is ' $n$ kennis van God se welwillendheid (benevolentia) wat, gegrond op die waarheid van sy genadige belofte in Christus, deur die Heilige Gees aan ons verstand geopenbaar word en in ons hart verseël word. Die kennis speel 'n belangrike rol in Calvyn se geloofsbeskouing. Hy omskrywe ook in sy Geneefse Kategismus die geloof as ' $n$ sekere en vaste kennis van God se liefde jeens ons: . . „ut dicamus certam esse al stabilem cognitionem paternae erga nos Dei benevolentiae." In sy kommentaar op Dan. 11.32 sè Calvyn hierdie kennis het nie die betekenis van ' $n$ kille verbeelding nie; dit moet as geloof verstaan word. In die kommentaar op Hand. 16.31 noem hy die geloof 'n betroubare en onderskeje kennis van Christus, en in die kommentaar op Joh. 17.3 gebruik hy "kennis" en "geloof" as sinonieme. Sonder hierdie "cognitio" kan geen ware geloof bestaan nie (Komm. Hos. 6.6). Hy bedoel dit nie intellektualisties nie. Hy onderskei tussen "cognitio" en „sensus", dit is om te begryp"2. Begryp het te doen met die dinge wat onder ons waarnemingsvermoë val. Die geloofskennis rig hom op die bonatuurlike dinge, op God se openbaring in Jesus Christus $^{23}$. Dit is „longe sublimius" bo gewone intellektuele begrippe. 
Dit is 'n kennis wat alleen tot stand kom deur die verligtende werking van die Heilige Gees op die menslike verstand (illuminatio Spiritus). Daar kan geen enkele verbinding tussen Christus en sy weldade met die mens tot stand kom, behalwe deur die Heilige Gees nie. Deur die Heilige Gees word die verstand vernuut en daar vloei die kennis uit voort wat bepalend is vir die geloof ${ }^{24}$. 'n Geloof sonder kennis en verstaan is vir Calvyn 'n onmoontlikheid. Leergierigheid, eerbied vir die leer, noem die Heilige Gees al geloof. „Ubi nulla est Dei cognitio certa, nulla est etiam religio et pietas prorsus exstincta est et fides abolita". Dit wil sê geen dooie kennis nie, maar 'n kennis wat in die hart woon (,non otiosa frigidaque notitia, sed quae homines, prius a Deo aversos, sub eius imperium restituat" - Komm. Hand. 11.21). Hierdie kennis het 'n besondere karakter. Dit is nie 'n neutrale kennis nie, dit is geïnteresseerde kennis ${ }^{25}$. Dit het sy voorwerp in die goddelike wil, dit is kennis van God se welwillendheid teenoor ons ${ }^{26}$ („divinae erga nos benevolent'ae"). Dit is 'n heilsame kennis wat ons na die beeld van God verander. Dit is ' $n$ kennis wat ons harte laat ontvlam tot die liefde vir Christus (,Non est frigida notitia, sed quae corda nostra inflammat in amorem Christi"). Dit is 'n kennis wat die hele mens in beweging bring wat die hart vanwaar die uitgange van die lewe is, beheers, nie 'n intellektualistiese, spekulatiewe kennis nie, maar 'n werksame, eksistensiële, bevindelike, religieus-etiese kennis. Dit is nie ' $n$ vae kennis wat eintlik homself verloor in die newelbeelde van gevoel en aandoening nie, maar dit is gegrond, belynd, welbewus en welversekerd. Dit is ' $n$ kenn's van God en sy beloftes. Die karakter van hierdie kennis hou in dat dit steeds hyg na vermeerdering dat dit honger en dors na die Woord van die lewe. Hierdie kennis is 'n kennis van die hart. Dit is saligmakend omdat dit aan ons hart rus bring. Uit hierdie kennis volg die toestemming, dit wil sê die hartlike omhelsing en beaming van die hele waarheid van God in wet en evangelie ${ }^{27}$.

\section{Fiducia}

Die innigste, teerste en saligste werksaamheid van die geloof is die vertroue waardeur ' $n$ mens jou op Christus verlaat, soos Hy aan ons van die Vader geskenk is (Rom. 10.10). Calvyn noem die geloof 'n ,assensio" (instemming) en 'n ,persuasio" (oortuiging). Dit ontstaan deur ' $n$ oorwin word deur die waarheid van God waarby ons persoonlik betrokke is en weet dat dit inderdaad God is en nie ' $n$ mens wat ons aangespreek het nie. Die kennis is dus ook 'n vaste oortuiging van die hart, ${ }^{28}$ 'n vaste versekerheid wat uit die waarheid van God verkry word. Hierdie kennis rig hom op die hele Woord van God en kragtens die persoonlike en ook objektiewe versekering van die Heilige Gees is dit geloofsdaad van die hele mens, met hoof en hart 29 .

Wanneer Calvyn oor die kennis en die oortuiging spreek, betrek hy onmiddellik die vertroue (fiducia) daarby. Die vertroue kom regstreeks uit die oortuiging voort. Uit die vaste oortuiging van die Vaderlike goedgunstigheid van God (paterna Dei benevolentia) vloei 
voort sowel die sekerheid aangaande ons behoud (salutis certitudo) as die ongestoorde vrede in ons gemoed (tranquilla animae securi$\operatorname{tas}^{30}$. Die oortuiging en die vertroue is op dieselfde voorwerp gerig wat tegelykertyd albei se grondslag is: die waarheid van die goddelike Woord". Die Heilige Skrif gebruik die woord "geloof" vir ,vertroue"32. Hy wat die geloof van die vertroue skei, is soos een wat aan die son sy gloed en lig probeer ontneem, want nêrens word die geloof sonder sy vrugte gevind nie. Die fiducia is in die geloof opgesluit ${ }^{33}$. Die geloof met die hart as sy setel is instemming, gehoorsaamheid, oortuiging, gemeenskap, vertroue. Die krag van die geloof is daarin geleë dat dit aan God se beloftes vasklem, dat dit in die volbragte werk van Christus rus en also van nature sekerheid is. Hier word nie geopereer met 'n twyfelagtige en veranderlike mening (dubia et versatilis opinio) of 'n duistere, verwarde gedagte (conceptio) nie. Dit trek sy lewenssap uit die gesonde leer (doctrina) soos in die Heilige Skrif geopenbaar ${ }^{34}$. Dit is dje betroubare fondament. Die Skrif is die enigste fidei regula wat vera et certa is. Die geloof is 'n vaste en sekere oortuiging van God se welwillendheid (benevolentia) jeens ons, gegrond in die beloftes van die genadeverbond, soos in die Woord geopenbaar, deur die Heilige Gees vir ons verstand geopen en in ons harte verseël ${ }^{35}$. Die geloof verenig ons met Christus deur Wie ons die sekerheid besit van God se liefde en laat ons met Hom saam groei ${ }^{36}$. Calvyn aarsel nie om te sê dat ons sekerheid moet word tot stoutmoedigheid wat selfs duiwels en engele uitdaag nie, omdat die gewete vas rus in die Woord en die belofte van God en daarin vrede en kalmte gewaarborg vind.

Die geloof met die sekerheid as bestanddeel is in homself tog swak. Ons is swak, sê Calvyn, maar die saligheid is vas ${ }^{37}$. Die geloof is meestal klein of middelmatig ${ }^{38}$, terwyl God dit tog die erenaam van geloof waardig keur. Die geloof bly onvolkome, want net so onmoontlik as wat dit is om 'n toring van water op te rig, is dit om ons geloof te vervolmaak. Maar dit sluit die sekerheid en die opregtheid van die geloof nie uit nie, maar in ${ }^{39}$, al het die gelowige 'n voortdurende stryd met sy eie gebrek aan vertroue. Die geloof is egter 'n palmboom wat teen alle moeilikhede in strewe en hom omhoog hef. Te midde van veelvuldige skokke ondersteun die geloof die harte van die gelowiges. Calvyn verwys na Ps. $46.6 ; 43.5 ; 31.23$ en 116.7. Die betrokkenheid op die Woord, op die waarheid self, gee aan die geloof sy vastheid ${ }^{40}$. Die Woord is dan soos 'n spieël waarin die geloof God aanskou ${ }^{4}$. Die Heilige Gees lê die verbinding tussen die gelowiges en die Woord wat die gewaad is waarin Christus tot ons kom. Daarom is die Heilige Skrif vir ons genoegsaam.

\section{Die vreugde wat die sekerheid bied}

Die geloof rus nie op menslike gissing soos die Skolastieke meen nie, maar dit rus op objektiewe sekerheid, al is dit die geval dat die gelowige in hierdie gebroke, sondige wêreld 'n voortdurende stryd met sy eie gebrek aan vertroue het. Van der Linde wys daarop ${ }^{42}$ dat die sekerheid van die geloof volgens Calvyn 'n titaniese indruk 
kan wek as ons nie goed in gedagte hou die uitdruklike beklemtoning by Calvyn dat hierdie sekerheid tog ook vrees en bestryding inhou nie. Hy sê die sekerheid is daar ondanks die vrees, en wie nooit gevrees het nie, het ook nooit geglo nie ${ }^{43}$ "qui fiduciam imaginatur omni timore vacuam, numquam gustarunt quidnam sit vera fides." Colvyn verklaar dat die geloof hier gemeng bly met ongelowigheid - dit is 'n siekte wat by ons diep ingewortel is. Hy beskou twyfel as die ergste wat 'n Christen kan oorkom. Twyfel het sy oorsprong nie uit die nuwe nie, maar uit die ou mens. Dit mag nie gekoester en aangekweek word nie, maar, sê Calvyn, die feit is dat daar in die gelowige nog velerlei twyfel en besorgdheid kan woon. Dit mag egter nie as normaal aangeprys word nie. Dit is altyd sonde en dit moet bestry word. Nie twyfel en vrees nie, maar vastigheid en sekerheid moet as die normale toestand van die geestelike lewe beskou word. Die geloof is volgens sy aard met alle twyfel in stryd die sekerheid word nie later van buite af daaraan toegevoeg nie. „Totam fidei naturam ignorant, qui eam dubitatione miscent" 44 . Die sekerheid is van die begin af in die geloof aanwesig en kom op sy tyd daaruit voort. Dit is 'n gawe van God, 'n werking van die Heilige Gees (Rom. 8.15; Gal. 4.6; Rom. 8 38; 2 Kor. 1.22 ; Efes. 1.13, 14; 4.30). Die certitudo fidei gee krag en steun aan die Christelike lewe ${ }^{45}$. Wat Calvyn bely: klink deur in onder andere die Dordtse Leerreëls V, 10 en 11: „Hierdie sekerheid spruit... nie voort uit enige besondere openbaring wat sonder of buite die Woord plaasgevind het nie, maar uit die geloof aan die beloftes van God wat Hy in sy Woord baie oorvloedig tot ons troos geopenbaar het; uit die getuienis van die Heilige Gees wat saam met ons gees getuig dat ons kinders en erfgename van God is, en eindelik uit die ernstige en heilige strewe na 'n goeie gewete en goeie werke. En as die uitverkorenes van God in hierdie wêreld hierdie vaste troos dat hulle die oorwining sal behou en hierdie onfeilbáre pand van die ewige heerlikheid nie sou besit nie, dan sou hulle van al die mense die ellendigste wees." Dit is vir Calvyn uit die Heilige Skrif duidelik dat die geloof uit die vrugte wat dit dra in versekerdheid groei. In hierdie verband kan onder meer na 2 Petr. $1.5-10$; 1 Joh. $2.3 ; 2.5,6$ en 3.14 verwys word. Hierdie waarheid klink later deur in ons Belydenisskrifte Vergelyk bv. vrae 64 en $86, \mathrm{H}$. Kateg. Die vrugte is nie 'n grond nie, maar 'n teken (Dordtse Leerreëls, 1, 6, 10, 12. Sillogismus practicus). Daar is sekerheid na die maat van die geloof (Luk. 17.5; 2 Kor. 10.15; 2 Thess. 1.3; Hebr. 5.13, 14. Dordtse Leerreëls V, 9, 10).

„Intussen getuig die Skrif dat die gelowiges in hierdie lewe teen verskillende twyfelinge van die vlees stry en, as hulle in sware aanvegtinge kom, nie altyd hierdie volle vertroue van die geloof en hierdie sekerheid van die volharding gevoel nie. Maar God, die Vader van alle vertroosting, laat nie toe dat hulle bo hulle kragte versoek word nie, maar Hy sal saam met die versoeking ook die uitkoms gee ( 1 Kor. 10.13) en Hy wek in hulle die versekerdheid van die volharding deur die Heilige Gees weer op."

Terwyl twyfel onrus, onvrede en ellende meebring, is die sekerheid van die geloof 'n onuitputlike bron van vreugde ${ }^{46}$, selfs in die 
bitterste omstandighede. Geen wonder dat Martin Luther hierdie geloof nader aandui as 'n goddelike lig in die verstand en 'n goddelike krag in die wil nie. Dit is helder en duidelik, innig en diep. Dit bring martelare voort, dit is teen die skavot en die brandstapel bestand. Dit gee volgens Calvyn die onuitroeibaarste sekerheid wat 'n blye oorwinningslied in die hart van die gelowige gebore laat word. So was dit met Calvyn self die geval en so geld dit deur die verbondsgeslagte van duisende en nogmaals duisende ander gelowiges, soos ons dit duidelik hoor spreek ook uit die woorde van die twee opstellers van die Heidelbergse Kategismus, Ursinus en Olevianus, albei dissipels van Calvyn. Ursinus gee hierdie kragtige getuienis in ' $n$ brief: "As u meen dat 'n mens van niemand met sekerheid kan sê dat hy salig sal word nie, dan het $u$ gelyk as $u$ daarby oor andere spreek, maar met betrekking tot onsself ... is hierdie gedagte verskriklik en Godslasterlik en werp dit die hele grond van die saligheid omver... Ek sou vir geen honderdduisend wêrelde wil dat ek só vér van my Christus moes wees en nie seker weet of ek sy eiendom is of nie."

En toe Oliveanus op sy sterfbed gelê en Alsted hom gevra het: "Is u sonder twyfel seker van u saligheid in Christus, soos u dit aan ander geleer het?" het hy geantwoord: „Certissimus!" (volkome seker!). Hierdie „,firma certitudo" het Calvyn as begenadigde dienskneg van die Here in sy diepste binneste met blydskap en dankbaarheid vervul in sy lewe en in sy sterwe. Die sekerheid van die geloof was vir hom 'n onmisbare vereiste, dit was absoluut noodsaaklik, dit is 'n sekerheid wat op 'n onwankelbare grondslag rus en dit is 'n sekerheid wat vreugde, 'n diepe vrede en rus in die hart te weeg bring.

Calvyn se woorde in sy testament, sy laaste wilsbeskikking, herinner sterk aan wat Paulus verklaar het toe die tyd van sy heengaan naby was; „Ek het die goeie stryd gestry; ek het die wedloop voleindig; ek het die geloof behou." Met heerlike geloofsversekerdheid kon Paulus dit uitspreek: „Verder is vir my weggelê die kroon van die geregtigheid wat die Here, die regverdige Regter, my in die dag sal gee" (2 Tim. $4.7,8$ ).

Hierdie woorde klink deur in wat Calvyn as laaste wilsbeskikking onder meer soos volg uitdruk: „Ek wil lewe en sterwe in die geloof en het geen ander hoop en vertroue behalwe daarop dat God my in genade aangeneem het nie. Hierop rus my hele saligheid; ek neem die genade aan wat Hy my in onse Here Jesus Christus bewys het en steun op die verdienste van sy lyde en sterwe, sodat daardeur al my sonde begrawe word. Ook smeek ek Hom dat Hy my wil was en reinig deur die bloed van ons groot Verlosser, wat vir alle arme sondaars vergiet is, sodat ek, terwyl ek sy beeld vertoon, voor sy aangesig kan verskyn"47.

Gelewer op die G.T.V. - Potchefstroom, 11 Februarie 1980.

Verwysings:

1) S. VAN DER LINDE, De leer van den Heiligen Geest bij Calvijn, H. Veenman en Zonen, Wageningen, 1943, p. 132.

2) L. BERKHOF, 1939, The assurance of Faith, W. B. Eerdmans Publishing 
Co., Grand Rapids, p. 19.

3) L. BERKHOF, a.w., p. 73.

4) JOHANNES CALVYN, Institusie of onderwysing in die Christelike Godsdiens, I, 7, 5; II, 2, 8. III, 2, 14 e.v.; 14, 8; 24.4 ens.

5) J. CALVYN, Institusie III, 2, 14, 15; vgl. I, 7, 5; II, 2, 8; III, 24, 4.

6) C. N. IMPETA, Christelijke Encyclopedie, J. H. Kok, Kampen, s.j., II, p. 262 e.v. Vgl. L. Praamsma, a.w., p. 20, 21, 38. 1967.

7) H. BAVINCK, Gereformeerde Dogmatiek, J. H. Kok, Kampen, I, p. 543.

8) AURELIUS AUGUSTINUS, Confessionum Libri 400, VII, 10.

9) KOMMENTAAR, GAL. 4.6: Diabolicum ... scholasticorum dogma, quod sublata certitudine, coniecturam moralem (quam appellant) in illius locum substituit... diabolum in:idelitas patrem, in omnibus papistarum scholis regnare. Calvyn praat van Rome se ,impium dogma".

10) J. CALVYN, Institusie III, 2, 2. Non in ignorantia, sed in cognitione sita est fides.

11) J. CALVYN, Institusie, III, 2, 3.

P. BRUNNER, Vom Glauben bei Calvin, 1925, p. 35.

G. C. BERKOUWER, Geloof en rechtvaardiging, 1949. Geloof en Heiliging, 1949. Geloof en Volharding; 1949.

12) J. CALVYN, Institusie III, 2, 4. Geloof is geleë in kennis van God en Christus (Joh, 17.3), nie in eerbied vir die kerk nie (Inst. III, 2,2).

13) J. CALVYN, Institusie III, 2, 8, 9.

P. J. S. de Klerk, Die reformatoriese geloofsbegrip, Die Westelike Stem, Potchefstroom, 1952, p. 4.

J. G. FEENSTRA, De Zekerheid des geloofs, J. H. Kok, Kampen, 1950, p. 15.

14) A. D. R. POLMAN, Christelijke Encyclopedie, J. H. Kok, Kampen, 1958, III, p. 137 e.v.

15) H. BAVINCK, Gereformeerde Dogmatiek, J. H. Kok, Kampen, 1967, IV, P. 110 .

H. J. COUVEE, Calvijn en Calvinisme, Broekhoff, N. V., Utrecht, 1936, p. 18.

16) H. BAVINCK, a.w., I, p. 542. (Geref. Dogm.).

H. BAVINCK, 1901, De wereldverwinnende kracht des geloofs. Kampen, p. 20.

17) Kommentaar op Rom. 11.34. De Reformatie, 1936, No. 42 e.v.

18) Kommentaar, Matth. 9.2; Matth. 12.44.

19) S. VAN DER LINDE. a.w., p. 135.

20) J. CALVYN, Institusie III, 2, 19.

21) J. CALVYN, Institusie III, 2, 7.

C. GRAAFLAND, De Zekerheid van het geloof. Ton Bolland, Amsterdam 1977, p. 13.

22) J. CALVYN, Institusie III, 2, 14.

23) J. CALVYN, Institusie III, 2, 14.

24) S. VAN DER LINDE, a.w., p. 141.

25) C. GRAAFLAND, a.w., p. 16.

26) J. CALVYN, Institusie III, $2,7$.

27) H. BAVINCK, a.w., I, p. 545 e.v.

28) J. CALVYN, Institusie III, 2, 2, 14.

29) C. GRAAFLAND, a.w., p.

30) Kommentaar, Rom. 8.33.

31) Kommentaar, Exod. 32.11; 
J. CALVYN, Institusie II, 12, 6; III, 2, 11 en 33.

32) J. CALVYN, Institusie III, 2, 15; Kommentaar, Efes. 3.12.

33) J. CALVYN, Institusie III, 2, 17 e.v.; C. HODGE, Systematic Theology, C. Scribner and co., New York, 1891, III, p. 107.

34) Kommentaar van J. Calvyn, Hebr. 11.11.

35) J. CALVYN, Institusie III, 2, 7.

36) J. CALVYN, Kommentaar, Joh. 6.35 en Efes. 3.12.

37) J. CALVYN, Kommentaar, 1 Petr. 1.5.

38) J. CALVYN, Kommentaar, Efes. 3.12.

J. CALVYN, Kommentaar 1 Thess, 1.12.

39) J. CALVYN, Institusie III, 2, 17.

40) J. CALVYN, Institusie III, 2, 15.

41) J. CALVYN, Institusie III, 2, 6.

42) S. VAN DER LINDE, a.w., p. 134.

43) Kommentaar, Gen. 32.6.

44) Kommentaar, 1 Kor. 2.12; Hebr, 10.22.

45) J. CALVYN, Institusie III, 2, 14 e.v. Vgl. Dh. 1, 12; V, $9-12 ; H$. Bavinck, a.w., IV, p. 213 e.v.

46) J. VAN GENDEREN, Christelijke Encyclopedie, J. H. Kok, Kampen 1961, VI, p. 674.

L. BERKHOF, 1939, The assurance of faith, W.m. Eerdmans Publishing Co., Grand Rapids, p. 14.

A. DE LIGNE, 1962, Geloof, T. Wever, Franeker, p. 50.

S. P. DEE, 1918, Het geloofsbegrip van Calvijn, J. H. Kok, Kampen, p. 27, 36.

47) L. PRAAMSMA, S. J., Calvijn, Zomer en Keunings Uitgeversmaatschappij. Wageningen, p. 251/252. 